\title{
Superparamagnetic Iron Oxide for Identifying Sentinel Lymph Node in Breast Cancer after Neoadjuvant Chemotherapy: Feasibility Study
}

\author{
Andrzej Kurylcio ${ }^{1}$, Zuzanna Pelc ${ }^{1}{ }^{\mathbb{D}}$, Magdalena Skórzewska ${ }^{1}$, Karol Rawicz-Pruszyński ${ }^{1, *}$, Radosław Mlak ${ }^{2}$, \\ Katarzyna Gęca ${ }^{1}$, Katarzyna Sędłak ${ }^{1}$, Piotr Kurylcio ${ }^{1}$, Teresa Małecka-Massalska ${ }^{2}$ and Wojciech Polkowski ${ }^{1}{ }^{1}$ \\ 1 Department of Surgical Oncology, Medical University of Lublin, Radziwiłłowska 13 St., \\ 20-080 Lublin, Poland; andrzej.kurylcio@umlub.pl (A.K.); zuzanna.torun@gmail.com (Z.P.); \\ magdalena.skorzewska@umlub.pl (M.S.); katarzyna.geca@umlub.pl (K.G.); sedlak.katarz@gmail.com (K.S.); \\ p.kurylcio@gmail.com (P.K.); wojciech.polkowski@uml.edu.pl (W.P.) \\ 2 Department of Human Physiology, Medical University of Lublin, Radziwiłłowska 11 St., \\ 20-080 Lublin, Poland; radoslaw.mlak@uml.edu.pl (R.M.); teresa.malecka-massalska@umlub.pl (T.M.-M.) \\ * Correspondence: karolrawiczpruszynski@uml.edu.pl; Tel.: +48-531-81-37
}

check for updates

Citation: Kurylcio, A.; Pelc, Z; Skórzewska, M.; Rawicz-Pruszyński, K.; Mlak, R.; Gęca, K.; Sędłak, K.; Kurylcio, P.; Małecka-Massalska, T; Polkowski, W. Superparamagnetic Iron Oxide for Identifying Sentinel Lymph Node in Breast Cancer after Neoadjuvant Chemotherapy: Feasibility Study. J. Clin. Med. 2021, 10, 3149. https://doi.org/10.3390/ jcm10143149

Academic Editor: Ramon

Andrade De Mello

Received: 1 June 2021

Accepted: 15 July 2021

Published: 16 July 2021

Publisher's Note: MDPI stays neutral with regard to jurisdictional claims in published maps and institutional affiliations.

Copyright: (c) 2021 by the authors. Licensee MDPI, Basel, Switzerland. This article is an open access article distributed under the terms and conditions of the Creative Commons Attribution (CC BY) license (https:// creativecommons.org/licenses/by/ $4.0 /)$.

\begin{abstract}
Sentinel lymph node biopsy (SLNB) is a well-established procedure for staging clinically node-negative early breast cancer (BC). Superparamagnetic iron oxide (SPIO) demonstrated efficacy for nodal identification using a magnetic probe after local retroaeroal interstitial injection. Its benefits lie in its flexibility, which is an essential property in the global setting, where access to the isotope is difficult. To the best of our knowledge, this is the first study to evaluate the feasibility and safety of the SPIO for SLNB in BC patients treated with neoadjuvant chemotherapy (NAC). Seventy-four female patients were included. The median time of lymph node retrieval was $20 \mathrm{~min}$. The median number of resected sentinel nodes (SNs) was 4 . SN was detected in all patients. No serious adverse event was observed. SPIO in identifying SN in BC patients after NAC is feasible and oncologically safe.
\end{abstract}

Keywords: breast cancer; neoadjuvant chemotherapy; sentinel lymph node; SPIO

\section{Introduction}

Sentinel lymph node biopsy (SLNB) is a well-established procedure for staging clinically node-negative early breast cancer (BC), although the optimal surgical management of the axilla has been controversially discussed over the last two decades [1]. Due to its minimally invasive approach and low morbidity, SLNB established a new milestone replacing axillary lymph node dissection (ALND) [2,3]. Thus, the quality of life in BC patients undergoing nodal staging has improved significantly, with a substantial reduction of postoperative seroma, numbness, lymphodema, chronic pain or shoulder mobility problems [4-8]. Sentinel node (SN) detection in BC was introduced by Giuliano in 1994, using blue dye [3]. Krag [2] and Veronesi [9] implemented the use of radiotracer, Technetium99m (Tc99) labeled nano colloid with a handheld gamma probe for SN identification. The simultaneous use of a radioisotope with blue dye increased the SN detection rate up to $96-97 \%$, as shown in the AMAROS and ALMANAC trials [10,11]. The use of a radioactive tracer alone or in combination with blue dye has been recognized as a gold standard of SLNB $[4,10]$.

However, the existing drawbacks of the dual method, such as radiation exposure, nuclear medicine unit dependency, substantial legislative control and allergic reactions to blue dye, warranted a clinical need for new, non-radioactive methods of SN identification. Superparamagnetic iron oxide (SPIO) nanoparticles demonstrated efficacy for nodal using a magnetic probe before local retroaeroal interstitial injection. Clinical studies and meta-analyses compared the magnetic technique with standard radioactive localization in $B C[12-23]$ and revealed non-inferiority to the gold standard isotope technique, with 
or without blue dye. The SPIO particles have been used for more than 20 years as an intravenous contrast for magnetic resonance imaging [24]. SPIO has a comparable detection rate as the dual technique and has not been associated with allergic reactions [25]. It remains in SNs after injection in the breast for more than 30 days [23] and thus provides independence from nuclear medicine units. SPIO benefits lie in its flexibility, which is an essential property in the global setting where access to the isotope is difficult [25]. Magtrace (Endomagnetics Limited, Cambridge, UK) is a dark brown-brownish suspension of a dextran-coated nanoparticle $(60 \mathrm{~nm})$ [25]. It is designed for lymphatic uptake and filtering out in the SNs [26]. In previous studies, Sienna+ (Endomagnetics Limited), a magnetic tracer, was used, however, it required dilution with saline before injection. On the contrary, Magtrace, which contains the same SPIO nanoparticles, does not require dilution. Thus the injected tracer volume can be reduced. Magnetic particles are detected using a handheld magnetometer (SentiMag). Neoadjuvant chemotherapy (NAC) in early BC results in higher rates of breast-conserving therapy when compared to adjuvant chemotherapy, without compromising on distant recurrence, breast cancer survival or overall survival [27,28]. NAC is currently the standard of care in locally advanced BC [29]. For early BC management, ESMO recommends a treatment regimen based on anthracyclines (with or without taxanes), which reduces BC mortality by $30 \%$ and improves the efficacy of NAC independently of LN involvement [30]. According to the NCCN BC Guidelines, SLNB is recommended in patients with nodes clinically negative after NAC [31]. Proper LN status assessment remains crucial for further decisions considering adjuvant treatment [32]. Moreover, nodal staging after NAC reflects more accurately future prognosis than LN assessment before neoadjuvant treatment [33]. To the best of our knowledge, there are no reports on the usage of SPIO in SLN evaluation in BC after NAC. Therefore, this study aimed to evaluate the feasibility and safety of the SPIO for SLNB in BC patients treated with NAC.

\section{Materials and Methods}

After obtaining institutional review board approval (Bioethical Committee of the Medical University of Lublin, Ethic Code: Ke-0221-34-2013), we collected data from a prospectively maintained database of all patients operated on in early $\mathrm{BC}$ between February 2013 and December 2020 in the Department of Surgical Oncology, Medical University of Lublin, Poland. Some 74 patients were eligible for analysis.

\subsection{Neoadjuvant Chemotherapy}

NAC was administered according to national guidelines, depending on the clinical stage of the disease and molecular subtype. NAC preferred regimen was 4 cycles AC (doxorubicin $75 \mathrm{mg} / \mathrm{m}^{2}$ with cyclophosphamide $750 \mathrm{mg} / \mathrm{m}^{2}$ ) administered every 3 weeks (conventional) or 2 weeks (dose-dense), followed by 12 cycles of weekly paclitaxel $\left(80 \mathrm{mg} / \mathrm{m}^{2}\right)$ or docetaxel at three-week intervals $\left(100 \mathrm{mg} / \mathrm{m}^{2}\right)$. Human epidermal growth factor receptor (HER2)-positive patients additionally received HER2-targeted therapy.

\subsection{Sentinel Lymph Node Biopsy}

We used a handheld magnetometer (SentiMag ${ }^{\circledR}$, (Sysmex Europe GmBH, Hamburg, Germany) to detect the $\mathrm{SNs}$, both before and after skin incision. As magnetic tracers we used Sienna $+{ }^{\circledR}$, (Sysmex Europe GmBH, Hamburg, Germany) (2 mL diluted in saline, obtaining a final volume of $5 \mathrm{~mL}$ ) and Magtrace ${ }^{\circledR}$ (Endomagnetics Limited, Cambridge, UK), (from 06.2019; undiluted $1 \mathrm{~mL}$ ). SPIO injection may cause skin staining for more than a year. This is seen almost exclusively after BCS. To avoid skin staining, SPIO was injected deeply into the subareolar interstitial tissue at least 18-24 h before SLNB. Before skin incision, the SPIO injection site and the hot spots of the axillary area were measured with the SentiMag ${ }^{\circledR}$ probe. In order to avoid interference with the magnetometer, polymer retractors and forceps were used while detecting the SLNs with the SentiMag ${ }^{\circledR}$ probe. All LNs marked with SPIO tracer were excised. The intraoperative SLNs identification was based on the node's handheld magnetometer's indications and/or brown staining. All 
identified SN were removed until the background signal was less than $10 \%$ of its highest value during SLNB. Therefore, SLNB was stopped when the residual activity in the axilla was less than $10 \%$.

\subsection{Statistical Analysis}

All statistical analyses were performed using MedCalc 15.8 (MedCalc Software, Ostend, Belgium). Median, interquartile range and minimum-maximum were used to summarize continuous variables when appropriate, and frequency and percentage were used to summarize categorical variables.

\section{Results}

\subsection{Clinical and Pathological Characteristics of the Enrolled Patients}

The study group consisted of female patients only. The median age was 55.5 years (range: 26-83), and the median BMI was 26 (17.2-42.2). The highest percentage of tumors was located in the upper outer quadrant $(43 \%)$. The most common diagnosis was invasive ductal carcinoma $(71.6 \%)$. Nine patients $(8.2 \%)$ were clinically node-positive $(\mathrm{cN}+)$ prior to NAC, whereas all patients were clinically node-negative after neoadjuvant treatment (ycN0) in ultrasonographical re-staging. Over half of the patients had complete tumor regression ypT0 $(56.8 \%)$, whereas sixty-one patients had pathologically negative LNs, ypN$(82.4 \%)$. Most of the patients had a positive ER $(63.1 \%)$ and PR $(60 \%)$ receptor status. However, HER2 expression was increased in only $32.4 \%$ of the cases. A high level of Ki67 was recorded in $75.4 \%$ of patients. Detailed demographic and clinical characteristics of the patients enrolled in the study are shown in Table 1.

Table 1. Demographic and clinical characteristics of the patients.

\begin{tabular}{|c|c|}
\hline Variable & Study Group $(n=74)$ \\
\hline \multicolumn{2}{|l|}{ Age (years) } \\
\hline median & 55.5 \\
\hline interquartile range & $43-64$ \\
\hline $\min -\max$ & $26-83$ \\
\hline$\geq 65$ & $18(24.3 \%)$ \\
\hline$<65$ & $56(75.7 \%)$ \\
\hline \multicolumn{2}{|l|}{$\operatorname{BMI}\left(\mathrm{kg} / \mathrm{m}^{2}\right)$} \\
\hline Median (26) & 26 \\
\hline Interquartile range & $22.2-28.6$ \\
\hline Min-max & $17.2-42.2$ \\
\hline Underweight $(<18.5)$ & $1(1.4 \%)$ \\
\hline Normal (18.5-24.9) & $27(36.5 \%)$ \\
\hline Overweight (25.0-29.9) & $32(43.2 \%)$ \\
\hline Obese $(\geq 30.0)$ & $14(18.9 \%)$ \\
\hline \multicolumn{2}{|l|}{ Tumor location in the breast } \\
\hline Central & $17(23 \%)$ \\
\hline Upper outer quadrant & $32(43.1 \%)$ \\
\hline Upper inner quadrant & $2(2.7 \%)$ \\
\hline Lower inner quadrant & $10(13.5 \%)$ \\
\hline Histologic type & \\
\hline
\end{tabular}


Table 1. Cont.

\begin{tabular}{|c|c|}
\hline Variable & Study Group $(n=74)$ \\
\hline Invasive ductal carcinoma & $53(71.6 \%)$ \\
\hline Non-special type & $15(20.3 \%)$ \\
\hline Other & $6(8.1 \%)$ \\
\hline \multicolumn{2}{|l|}{ Nuclear grade } \\
\hline G1 & $7(9.5 \%)$ \\
\hline G2 & $32(43.2 \%)$ \\
\hline G3 & $35(47.3 \%)$ \\
\hline \multicolumn{2}{|l|}{ ypT } \\
\hline pT0 & $42(56.8 \%)$ \\
\hline pT1a & $2(2.7 \%)$ \\
\hline pT1b & $1(1.4 \%)$ \\
\hline pT1c & $17(23 \%)$ \\
\hline pT2 & $12(16.2 \%)$ \\
\hline \multicolumn{2}{|l|}{ ypN } \\
\hline Negative & $61(82.4 \%)$ \\
\hline Positive & $13(17.6 \%)$ \\
\hline \multicolumn{2}{|l|}{ Molecular subtype } \\
\hline Luminal A & $6(8.1 \%)$ \\
\hline Luminal B (HER2 negative) & $23(31.2 \%)$ \\
\hline Luminal B (HER2 positive) & $16(21.6 \%)$ \\
\hline HER 2+ & $7(9.4 \%)$ \\
\hline Triple negative & $22(29.7 \%)$ \\
\hline
\end{tabular}

\subsection{Perioperative Characteristics of the Enrolled Patients}

Thirty-seven patients $(50 \%)$ underwent breast-conserving surgery. Surgical margin was achieved in seventy patients $(94.6 \%)$. The median time of lymph node retrieval was 20 min (range: 10-50). Lymphadenectomy was performed in thirteen patients $(17.6 \%)$. The median number of resected SNs was 4 (range: 1-10). SN was detected in all patients. No serious adverse event was observed. Detailed perioperative data is shown in Table 2.

Table 2. Perioperative characteristics.

\begin{tabular}{cc}
\hline Variable & Study Group $(\boldsymbol{n = 7 4 )}$ \\
\hline Type of breast surgery & \\
\hline BCS & $37(50 \%)$ \\
\hline MRM & $1(1.4 \%)$ \\
\hline SM & $23(31.1 \%)$ \\
\hline NSM+IBR & $13(17.6 \%)$ \\
\hline Largest dimension of the tumor $(\mathrm{mm})$ & 20 \\
\hline median & $13-30$ \\
\hline interquartile range & $1.5-60$ \\
\hline min-max
\end{tabular}


Table 2. Cont.

\begin{tabular}{cc}
\hline Variable & Study Group $(\boldsymbol{n = 7 4 )}$ \\
\hline Surgical margin & $70(94.6 \%)$ \\
\hline R0 & $4(5.4 \%)$ \\
\hline R1 & 20 \\
\hline Time of lymph node resection (min) & $18.7-25$ \\
\hline median & $10-50$ \\
\hline interquartile range & 4 \\
\hline min-max & $3-5$ \\
\hline SN (number, resected) & $1-10$ \\
\hline median & \\
\hline interquartile range & \\
\hline min-max & \\
\hline
\end{tabular}

$\overline{\mathrm{BCS}}$, breast-conserving surgery; MRM, modified radical mastectomy; SM, simple mastectomy; NSM+IBR, nipplesparing mastectomy with immediate breast reconstruction; $\mathrm{SN}$, sentinel node.

\section{Discussion}

Although Rubio et al. provided a report on the outcome of SLN after NAC using a dual tracer (SPIO-TC99) at ASCO annual meeting [34], to the best of our knowledge, this is the first study that evaluated the feasibility and safety of SPIO for SLNB in BC patients after NAC. SLNs (Figure 1) were successfully identified in all patients, and no postoperative complications were observed. The tumor recurrence after initial response to treatment remains a clinical challenge, despite recent advances in BC management [35]. Moreover, the appropriate axillary treatment in the context of NAC is not clearly established. We have demonstrated that SPIO-guided SLNB could be successfully used in SN detection after NAC (100\%). A mean number of resected SLN was four. When harvesting two or three SLN, the false-negative ratio (FNR) remains under 10\%, which is considered oncologically safe [36-39].

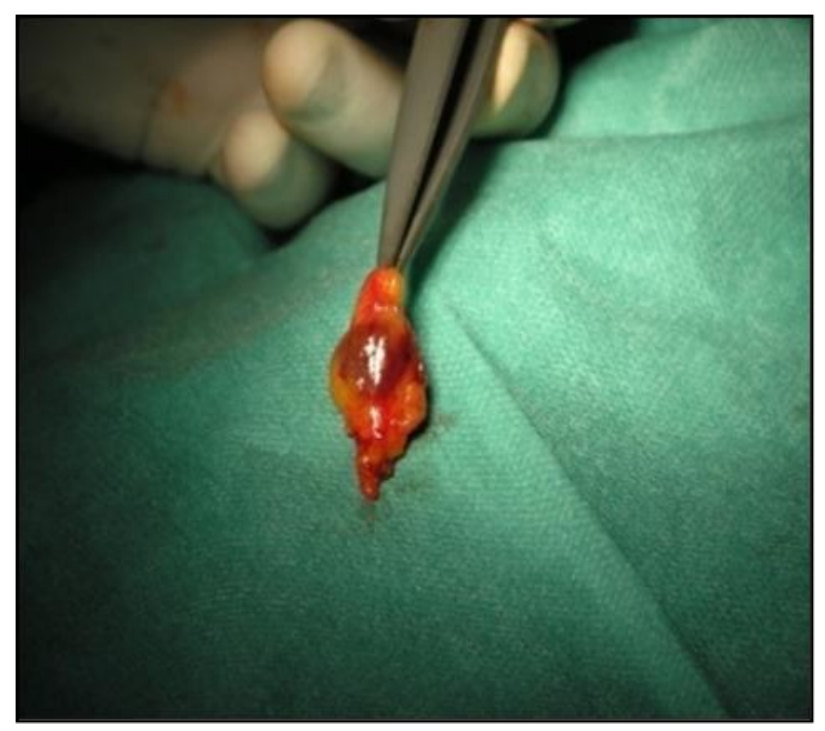

Figure 1. Sentinel node retrieved with superparamagnetic iron oxide (SPIO).

SPIO may be a potentially optimal tracer for SLNB after NAC in BC patients due to high SN retrieval number and low FNR compared with conventional methods [40]. Bezire et al. evaluated the feasibility of and the tolerance to radiotherapy after using the magnetic detection method for SLNB. The SN identification rate with SPIO was $99.7 \%$, which is 
consistent with our result. MONOS study [41] evaluated the use of SPIO as a sole tracer and the efficacy of tracer injection in the preoperative setting. SPIO was concluded as a safe and cost-effective alternative to dual technique using $99 \mathrm{~m}$ Tc and blue dye with simplified logistics, improved performance and skin staining prevention. When compared to dualtracers, usage of SPIO saves over 20,000\$ annually [23]. Alarcon et al. assessed the efficacy and accuracy of the clipped node's wire localization to reduce the false-negative rate of SN retrieval. For intraoperative localization, wire marking has proven to be a safe procedure in which removal of SN was achieved in all patients [42]. Similarly, the detection rate of SPIOguided SLNB in our study was 100\%, resulting in 0\% FNR. NCCN Guidelines recommend SLNB in selected cases with ycN0 status. Among cN+ patients, SLNB after NAC has a $>10 \%$ false-negative rate. Removal of at least $3 \mathrm{SN}$ improves this rate. In our study, median $\mathrm{SN}$ retrieval was 4 . In a study conducted by Wong et al., patients with stage I-III BC who underwent NAC demonstrated acceptable short-term locoregional control associated with SLNB alone in cN1-2/ypN0 patients. SLNB was the most accurate minimally invasive method for staging the axilla and evaluating residual nodal disease [43]. Chun et al., in an analysis of 676 patients, suggested SLNB alone may be a possible option for patients with 1-3 SN+ BC after NAC without compromise of recurrence or overall survival [44]. Since SLN surgery in node-positive patients after NAC is not oncologically inferior to ALND for locoregional recurrence, it is becoming more widely incorporated into clinical practice [45]. With advances in genomics, imaging, and multimodal therapy, the role and extent of axillary surgery for staging should be continually reevaluated [45]. On the other hand, van der Noordaa et al. recently suggested omitting SNLB in patients with triple-negative BC, HER2+ tumors or after achieving breast radiological complete response in MRI [46]. In the EUBREAST-01 trial, axillary surgery will be eliminated for initially clinical nodenegative patients with complete radiologic remission and breast $\mathrm{pCR}$ in the lumpectomy specimen [47]. Considering the increasing number of patients qualified for NAC, SLNB remains an essential tool for evaluating systemic treatment from the oncological perspective. According to Erdahl et al., evaluation of the N stage after NAC results in a more adequate prediction of the patient's residual disease severity and response to systemic therapy [32]. These outcomes further determine adjuvant treatment, targeted or hormone therapy for patients previously treated with NAC [48]. However, preoperative therapy increases the complexity of SNLB, indicating the need for tailored, multidisciplinary management based on clinical counseling and standardization of qualification for SNLB after NAC [49]. SIPOguided SLNB reduces the hospitalization rate and omits lymphoscintigraphy in the nuclear medicine unit, thus possibly shortening the treatment period. This is coherent with the clinical focus on reducing delays between individual treatments in $\mathrm{BC}$ patients to improve overall survival [50]. Magnetic-guided SLNB can omit isotope-based axillary mapping and allows a novel tailored approach to $\mathrm{BC}$ patients [51].

\section{Conclusions}

SPIO is a feasible and oncologically safe method for identifying SN in BC patients after NAC.

Author Contributions: Conceptualization, A.K., K.R.-P., Z.P., M.S., P.K.; Methodology, R.M., K.S., K.G., T.M.-M.; Software, R.M., K.G., P.K.; Validation: A.K., Z.P., K.R.-P., M.S., W.P.; Formal analysis, R.M., K.S., K.G., P.K.,T.M.-M.; Investigation, A.K., K.R.-P., Z.P., M.S.; Data curation, K.R.-P., A.K., Z.P., M.S., K.S., K.G.; Writing-original draft preparation, A.K., Z.P., M.S., K.R.-P.; Writing-review and editing, K.R.-P., A.K., W.P., T.M.-M.; Supervision: W.P., T.M.-M. All authors have read and agreed to the published version of the manuscript.

Funding: This research received no external funding.

Institutional Review Board Statement: The study was conducted according to the guidelines of the Declaration of Helsinki and approved by the Institutional Review Board-Bioethical Committee of Medical University of Lublin, Ethic Code: Ke-0221-34-2013).

Informed Consent Statement: Informed consent was obtained from all subjects involved in the study. 
Data Availability Statement: Not applicable.

Conflicts of Interest: The authors declare no conflict of interest.

\section{References}

1. Banys-Paluchowski, M.; Gasparri, M.L.; de Boniface, J.; Gentilini, O.; Stickeler, E.; Hartmann, S.; Thill, M.; Rubio, I.T.; Di Micco, R.; Bonci, E.-A.; et al. Surgical Management of the Axilla in Clinically Node-Positive Breast Cancer Patients Converting to Clinical Node Negativity through Neoadjuvant Chemotherapy: Current Status, Knowledge Gaps, and Rationale for the EUBREAST-03 AXSANA Study. Cancers 2021, 13, 1565. [CrossRef] [PubMed]

2. Krag, D.; Weaver, D.; Alex, J.; Fairbank, J. Surgical resection and radiolocalization of the sentinel lymph node in breast cancer using a gamma probe. Surg. Oncol. 1993, 2, 335-340. [CrossRef]

3. Giuliano, A.E.; Kirgan, D.M.; Guenther, J.M.; Morton, D.L. Lymphatic Mapping and Sentinel Lymphadenectomy for Breast Cancer. Ann. Surg. 1994, 220, 391-401. [CrossRef] [PubMed]

4. Cody, H.S.; Fey, J.; Akhurst, T.; Fazzari, M.; Mazumdar, M.; Yeung, H.; Yeh, S.D.J.; Borgen, P.I. Complementarity of Blue Dye and Isotope in Sentinel Node Localization for Breast Cancer: Univariate and Multivariate Analysis of 966 Procedures. Ann. Surg. Oncol. 2001, 8, 13-19. [CrossRef] [PubMed]

5. Ashikaga, T.; Krag, D.N.; Land, S.R.; Julian, T.B.; Anderson, S.; Brown, A.M.; Ms, J.M.S.; Harlow, S.P.; Weaver, D.L.; Mamounas, E.P.; et al. Morbidity results from the NSABP B-32 trial comparing sentinel lymph node dissection versus axillary dissection. J. Surg. Oncol. 2010, 102, 111-118. [CrossRef] [PubMed]

6. $\quad$ Lucci, A.; McCall, L.M.; Beitsch, P.D.; Whitworth, P.W.; Reintgen, D.S.; Blumencranz, P.W.; Leitch, A.M.; Saha, S.; Hunt, K.K.; Giuliano, A.E. Surgical Complications Associated With Sentinel Lymph Node Dissection (SLND) Plus Axillary Lymph Node Dissection Compared With SLND Alone in the American College of Surgeons Oncology Group Trial Z0011. J. Clin. Oncol. 2007, 25, 3657-3663. [CrossRef] [PubMed]

7. Mansel, R.E.; Fallowfield, L.; Kissin, M.; Goyal, A.; Newcombe, R.G.; Dixon, J.M.; Yiangou, C.; Horgan, K.; Bundred, N.; Monypenny, I.; et al. Randomized Multicenter Trial of Sentinel Node Biopsy Versus Standard Axillary Treatment in Operable Breast Cancer: The ALMANAC Trial. J. Natl. Cancer Inst. 2006, 98, 599-609. [CrossRef] [PubMed]

8. Del Bianco, P.; Zavagno, G.; Burelli, P.; Scalco, G.; Barutta, L.; Carraro, P.; Pietrarota, P.; Meneghini, G.; Morbin, T.; Tacchetti, G.; et al. Morbidity comparison of sentinel lymph node biopsy versus conventional axillary lymph node dissection for breast cancer patients: Results of the sentinella-GIVOM Italian randomised clinical trial. Eur. J. Surg. Oncol. (EJSO) 2008, 34, 508-513. [CrossRef] [PubMed]

9. Veronesi, U.; Paganelli, G.; Galimberti, V.; Viale, G.; Zurrida, S.; Bedoni, M.; Costa, A.; de Cicco, C.; Geraghty, J.G.; Luini, A.; et al. Sentinel-node biopsy to avoid axillary dissection in breast cancer with clinically negative lymph-nodes. Lancet 1997, 349, 1864-1867. [CrossRef]

10. Straver, M.E.; Meijnen, P.; Van Tienhoven, G.; Van De Velde, C.J.H.; Mansel, R.E.; Bogaerts, J.; Duez, N.; Cataliotti, L.; Klinkenbijl, J.H.G.; Westenberg, H.A.; et al. Sentinel Node Identification Rate and Nodal Involvement in the EORTC 10981-22023 AMAROS Trial. Ann. Surg. Oncol. 2010, 17, 1854-1861. [CrossRef] [PubMed]

11. Goyal, A.; Newcombe, R.G.; Chhabra, A.; Mansel, R.E.; on behalf of the ALMANAC Trialists Group. Factors affecting failed localisation and false-negative rates of sentinel node biopsy in breast cancer-results of the ALMANAC validation phase. Breast Cancer Res. Treat. 2006, 99, 203-208. [CrossRef]

12. Rubio, I.; Diaz-Botero, S.; Esgueva, A.; Rodriguez, R.; Cortadellas, T.; Cordoba, O.; Espinosa-Bravo, M. The superparamagnetic iron oxide is equivalent to the Tc99 radiotracer method for identifying the sentinel lymph node in breast cancer. Eur. J. Surg. Oncol. (EJSO) 2015, 41, 46-51. [CrossRef] [PubMed]

13. Douek, M.; On behalf of the SentiMAG Trialists Group; Klaase, J.; Monypenny, I.; Kothari, A.; Zechmeister, K.; Brown, U.; Wyld, L.; Drew, P.; Garmo, H. Sentinel Node Biopsy Using a Magnetic Tracer Versus Standard Technique: The SentiMAG Multicentre Trial. Ann. Surg. Oncol. 2013, 21, 1237-1245. [CrossRef]

14. Thill, M.; Kurylcio, A.; Welter, R.; van Haasteren, V.; Grosse, B.; Berclaz, G.; Polkowski, W.; Hauser, N. The Central-European SentiMag study: Sentinel lymph node biopsy with superparamagnetic iron oxide (SPIO) vs. radioisotope. Breast 2014, 23, 175-179. [CrossRef]

15. Piñero-Madrona, A.; Torró-Richart, J.; De León-Carrillo, J.; De Castro-Parga, G.; Navarro-Cecilia, J.; Dominguez-Cunchillos, F.; Román-Santamaría, J.; Fuster-Diana, C.; Pardo-Garcia, R. Superparamagnetic iron oxide as a tracer for sentinel node biopsy in breast cancer: A comparative non-inferiority study. Eur. J. Surg. Oncol. (EJSO) 2015, 41, 991-997. [CrossRef] [PubMed]

16. Houpeau, J.-L.; Chauvet, M.-P.; Guillemin, F.; Bendavid-Athias, C.; Charitansky, H.; Kramar, A.; Giard, S. Sentinel lymph node identification using superparamagnetic iron oxide particles versus radioisotope: The French Sentimag feasibility trial. J. Surg. Oncol. 2016, 113, 501-507. [CrossRef] [PubMed]

17. Ghilli, M.; Carretta, E.; Di Filippo, F.; Battaglia, C.; Fustaino, L.; Galanou, I.; Rucci, P.; Fantini, M.; Roncella, M. The superparamagnetic iron oxide tracer: A valid alternative in sentinel node biopsy for breast cancer treatment. Eur. J. Cancer Care 2015, $26, \mathrm{e} 12385$. [CrossRef] [PubMed]

18. Teshome, M.; Wei, C.; Hunt, K.K.; Thompson, A.; Rodriguez, K.; Mittendorf, E.A. Use of a Magnetic Tracer for Sentinel Lymph Node Detection in Early-Stage Breast Cancer Patients: A Meta-analysis. Ann. Surg. Oncol. 2016, 23, 1508-1514. [CrossRef] [PubMed] 
19. Zada, A.; Peek, M.C.L.; Ahmed, M.; Anninga, B.; Baker, R.; Kusakabe, M.; Sekino, M.; Klaase, J.M.; Haken, B.T.; Douek, M. Meta-analysis of sentinel lymph node biopsy in breast cancer using the magnetic technique. Br. J. Surg. 2016, 103, 1409-1419. [CrossRef]

20. Alvarado, M.D.; Mittendorf, E.A.; Teshome, M.; Thompson, A.M.; Bold, R.J.; Gittleman, M.A.; Beitsch, P.D.; Blair, S.L.; Kivilaid, K.; Harmer, Q.J.; et al. SentimagIC: A Non-inferiority Trial Comparing Superparamagnetic Iron Oxide Versus Technetium-99m and Blue Dye in the Detection of Axillary Sentinel Nodes in Patients with Early-Stage Breast Cancer. Ann. Surg. Oncol. 2019, 26, 3510-3516. [CrossRef]

21. Taruno, K.; Kurita, T.; Kuwahata, A.; Yanagihara, K.; Enokido, K.; Katayose, Y.; Nakamura, S.; Takei, H.; Sekino, M.; Kusakabe, M. Multicenter clinical trial on sentinel lymph node biopsy using superparamagnetic iron oxide nanoparticles and a novel handheld magnetic probe. J. Surg. Oncol. 2019, 120, 1391-1396. [CrossRef]

22. Sekino, M.; Kuwahata, A.; Ookubo, T.; Shiozawa, M.; Ohashi, K.; Kaneko, M.; Saito, I.; Inoue, Y.; Ohsaki, H.; Takei, H.; et al. Handheld magnetic probe with permanent magnet and Hall sensor for identifying sentinel lymph nodes in breast cancer patients. Sci. Rep. 2018, 8, 1-9. [CrossRef]

23. Man, V.; Wong, T.T.; Co, M.; Suen, D.; Kwong, A. Sentinel Lymph Node Biopsy in Early Breast Cancer: Magnetic Tracer as the Only Localizing Agent. World J. Surg. 2019, 43, 1991-1996. [CrossRef]

24. Weissleder, R.; Elizondo, G.; Wittenberg, J.; Rabito, C.A.; Bengele, H.H.; Josephson, L. Ultrasmall superparamagnetic iron oxide: Characterization of a new class of contrast agents for MR imaging. Radiology 1990, 175, 489-493. [CrossRef] [PubMed]

25. Wärnberg, F.; Stigberg, E.; Obondo, C.; Olofsson, H.; Abdsaleh, S.; Wärnberg, M.; Karakatsanis, A. Long-Term Outcome After Retro-Areolar Versus Peri-Tumoral Injection of Superparamagnetic Iron Oxide Nanoparticles (SPIO) for Sentinel Lymph Node Detection in Breast Cancer Surgery. Ann. Surg. Oncol. 2019, 26, 1247-1253. [CrossRef] [PubMed]

26. Pouw, J.; Ahmed, M.; Anninga, B.; Schuurman, K.; Pinder, S.; Van Hemelrijck, M.; Pankhurst, Q.; Douek, M.; Haken, B.T. Comparison of three magnetic nanoparticle tracers for sentinel lymph node biopsy in an in vivo porcine model. Int. J. Nanomed. 2015, 10, 1235-1243. [CrossRef] [PubMed]

27. Derks, M.G.M.; van de Velde, C.J.H. Neoadjuvant chemotherapy in breast cancer: More than just downsizing. Lancet Oncol. 2018, 19, 2-3. [CrossRef]

28. Asselain, B.; Barlow, W.; Bartlett, J.; Bergh, J.; Bergsten-Nordström, E.; Bliss, J.; Boccardo, F.M.; Boddington, C.; Bogaerts, J.; Bonadonna, G.; et al. Long-term outcomes for neoadjuvant versus adjuvant chemotherapy in early breast cancer: Meta-analysis of individual patient data from ten randomised trials. Lancet Oncol. 2018, 19, 27-39. [CrossRef]

29. Barchiesi, G.; Mazzotta, M.; Krasniqi, E.; Pizzuti, L.; Marinelli, D.; Capomolla, E.; Sergi, D.; Amodio, A.; Natoli, C.; Gamucci, T.; et al. Neoadjuvant Endocrine Therapy in Breast Cancer: Current Knowledge and Future Perspectives. Int. J. Mol. Sci. 2020, 21, 3528. [CrossRef]

30. Cardoso, F.; Kyriakides, S.; Ohno, S.; Penault-Llorca, F.; Poortmans, P.; Rubio, I.T.; Zackrisson, S.; Senkus, E. Early breast cancer: ESMO Clinical Practice Guidelines for diagnosis, treatment and follow-up. Ann. Oncol. 2019, 30, 1194-1220. [CrossRef]

31. Gradishar, W.J.; Anderson, B.O.; Abraham, J.; Aft, R.; Agnese, D.; Allison, K.H.; Blair, S.L.; Burstein, H.J.; Dang, C.; Elias, A.D.; et al. Breast Cancer, Version 3.2020, NCCN Clinical Practice Guidelines in Oncology. J. Natl. Compr. Cancer Netw. 2020, 18, 452-478. [CrossRef]

32. Erdahl, L.M.; Boughey, J.C. Use of Sentinel Lymph Node Biopsy to Select Patients for Local-Regional Therapy After Neoadjuvant Chemotherapy. Curr. Breast Cancer Rep. 2014, 6, 10-16. [CrossRef] [PubMed]

33. Rouzier, R.; Extra, J.-M.; Klijanienko, J.; Falcou, M.-C.; Asselain, B.; Vincent-Salomon, A.; Vielh, P.; Bourstyn, E. Incidence and Prognostic Significance of Complete Axillary Downstaging After Primary Chemotherapy in Breast Cancer Patients with T1 to T3 Tumors and Cytologically Proven Axillary Metastatic Lymph Nodes. J. Clin. Oncol. 2002, 20, 1304-1310. [CrossRef]

34. Rubio, I.T.; Diaz-Botero, S.; Esgueva, A.J.; Espinosa-Bravo, M. Increased detection of sentinel nodes in breast cancer patients with the use of superparamagnetic iron oxide tracer. J. Clin. Oncol. 2014, 32, 100. [CrossRef]

35. Haynes, B.; Sarma, A.; Nangia-Makker, P.; Shekhar, M.P. Breast cancer complexity: Implications of intratumoral heterogeneity in clinical management. Cancer Metastasis Rev. 2017, 36, 547-555. [CrossRef] [PubMed]

36. Cavalcante, F.P.; Millen, E.C.; Zerwes, F.P.; Novita, G.G. Role of Axillary Surgery After Neoadjuvant Chemotherapy. JCO Glob. Oncol. 2020, 6, 238-241. [CrossRef]

37. Boileau, J.-F.; Poirier, B.; Basik, M.; Holloway, C.M.; Gaboury, L.; Sideris, L.; Meterissian, S.; Arnaout, A.; Brackstone, M.; McCready, D.R.; et al. Sentinel Node Biopsy After Neoadjuvant Chemotherapy in Biopsy-Proven Node-Positive Breast Cancer: The SN FNAC Study. J. Clin. Oncol. 2015, 33, 258-264. [CrossRef] [PubMed]

38. Kuehn, T.; Bauerfeind, I.; Fehm, T.; Fleige, B.; Hausschild, M.; Helms, G.; Lebeau, A.; Liedtke, C.; von Minckwitz, G.; Nekljudova, V.; et al. Sentinel-lymph-node biopsy in patients with breast cancer before and after neoadjuvant chemotherapy (SENTINA): A prospective, multicentre cohort study. Lancet Oncol. 2013, 14, 609-618. [CrossRef]

39. Boughey, J.C.; Suman, V.J.; Mittendorf, E.A.; Ahrendt, G.M.; Wilke, L.G.; Taback, B.; Leitch, A.M.; Kuerer, H.M.; Bowling, M.; Flippo-Morton, T.S.; et al. Sentinel Lymph Node Surgery After Neoadjuvant Chemotherapy in Patients with Node-Positive Breast Cancer. JAMA 2013, 310, 1455-1461. [CrossRef]

40. Qiu, S.-Q.; Zhang, G.-J.; Jansen, L.; De Vries, J.; Schröder, C.P.; de Vries, E.; Van Dam, G.M. Evolution in sentinel lymph node biopsy in breast cancer. Crit. Rev. Oncol. 2018, 123, 83-94. [CrossRef] 
41. Karakatsanis, A.; Daskalakis, K.; Stålberg, P.; Olofsson, H.; Andersson, Y.; Eriksson, S.; Bergkvist, L.; Wärnberg, F. Superparamagnetic iron oxide nanoparticles as the sole method for sentinel node biopsy detection in patients with breast cancer. Br. J. Surg. 2017, 104, 1675-1685. [CrossRef]

42. Alarcón, M.; Buch, E.; Julve, A.; Hernandorena, M.; Tajahuerce, M.; Rodríguez, H.; Bermejo, B.; Ramírez, J.; Burgués, O.; Díaz, S.; et al. Sentinel lymph node BIOPSY after neoadjuvant therapy in breast cancer patients with lymph node involvement at diagnosis. Could wire localization of clipped node improve our results? Surgeon 2021. [CrossRef] [PubMed]

43. Wong, S.M.; Basik, M.; Florianova, L.; Margolese, R.; Dumitra, S.; Muanza, T.; Carbonneau, A.; Ferrario, C.; Boileau, J.F. Oncologic Safety of Sentinel Lymph Node Biopsy Alone After Neoadjuvant Chemotherapy for Breast Cancer. Ann. Surg. Oncol. 2021, 28, 2621-2629. [CrossRef]

44. Chun, J.W.; Kim, J.; Chung, I.I.Y.; Ko, B.S.; Kim, H.J.; Lee, J.W.; Son, B.H.; Ahn, S.-H.; Lee, S.B. Comparison of survival outcomes for axillary surgery extent based on intraoperative sentinel lymph node biopsy result after neoadjuvant chemotherapy for breast cancer. Breast Cancer Res. Treat. 2021, 187, 647-655. [CrossRef] [PubMed]

45. Do, M.A.P.; Boughey, J.C. ASO Author Reflections: Sentinel Lymph Node Surgery After Neoadjuvant Chemotherapy for Node-Positive Breast Cancer: Is It Oncologically Safe? Ann. Surg. Oncol. 2020, 27, 707-708. [CrossRef]

46. Van der Noordaa, M.E.M.; van Duijnhoven, F.H.; Cuijpers, F.N.E.; van Werkhoven, E.; Wiersma, T.G.; Elkhuizen, P.H.M.; Winter-Warnars, G.; Dezentje, V.; Sonke, G.S.; Groen, E.J.; et al. Toward omitting sentinel lymph node biopsy after neoadjuvant chemotherapy in patients with clinically node-negative breast cancer. Br. J. Surg. 2021, 108, 667-674. [CrossRef]

47. Reimer, T.; Glass, A.; Botteri, E.; Loibl, S.; Gentilini, O.D. Avoiding Axillary Sentinel Lymph Node Biopsy after Neoadjuvant Systemic Therapy in Breast Cancer: Rationale for the Prospective, Multicentric EUBREAST-01 Trial. Cancers 2020, 12, 3698. [CrossRef]

48. Lee, S.B.; Kim, H.; Kim, J.; Chung, I.Y.; Kim, H.J.; Ko, B.S.; Lee, J.W.; Ahn, S.H.; Son, B.H. Prognosis according to clinical and pathologic lymph node status in breast cancer patients who underwent sentinel lymph node biopsy alone after neoadjuvant therapy. PLoS ONE 2021, 16, e0251597. [CrossRef]

49. Franceschini, G.; Di Leone, A.; Sanchez, A.M.; D'Archi, S.; Scardina, L.; Masetti, R. Update on the sentinel lymph node biopsy after neoadjuvant chemotherapy in breast cancer patient. Ann. Ital. di Chir. 2020, 9, 465-468.

50. Yung, R.; Ray, R.M.; Roth, J.; Johnson, L.; Warnick, G.; Anderson, G.L.; Kroenke, C.H.; Chlebowski, R.T.; Simon, M.S.; Fung, C.; et al. The association of delay in curative intent treatment with survival among breast cancer patients: Findings from the Women's Health Initiative. Breast Cancer Res. Treat. 2020, 180, 747-757. [CrossRef]

51. Hersi, A.-F.; Pistiolis, L.; Luberth, C.D.; Vikhe-Patil, E.; Nilsson, F.; Mohammed, I.; Bagge, R.O.; Wärnberg, F.; Eriksson, S.; Karakatsanis, A. Optimizing Dose and Timing in Magnetic Tracer Techniques for Sentinel Lymph Node Detection in Early Breast Cancers: The Prospective Multicenter SentiDose Trial. Cancers 2021, 13, 693. [CrossRef] [PubMed] 